\title{
Die Kasseler Liste
}

\section{Erhard Taverna}

Dr. med.

An der Documenta 2017 in Kassel konnte man einen Tempel der verbotenen Bücher bewundern. Ein gross dimensionierter Parthenon, gepflastert mit zehntausenden Umschlagbildern einst oder heute verbotener Werke aus der ganzen Welt. Eine kleine Gruppe von Germanisten hatte in kürzester Zeit eine Liste für das Projekt der argentinischen Künstlerin Marta Minujin zusammengestellt. Die Liste umfasste damals 70000 Titel, inzwischen sind es weit über 100000. Bekanntestes Vorbild ist immer noch der Index librorum prohibitorum der römischen Inquisition, ein Verzeichnis, das 1559 begann und bis zur Aufhebung 1965 rund 6000 Bücher umfasste. Die wenigsten Länder führen Zensurlisten. Vor allem in der NS-Zeit wurden verbotene Autoren akribisch aufgelistet. Fündig wurden die Forscher in Archiven der Sowjetischen Besatzungszone, dem Vorläufer der DDR und in Archiven des Habsburgerreiches. Ergiebige Befunde gaben Recherchen in Lateinamerika, in Osteuropa und der Türkei. Häufiger sind indi-

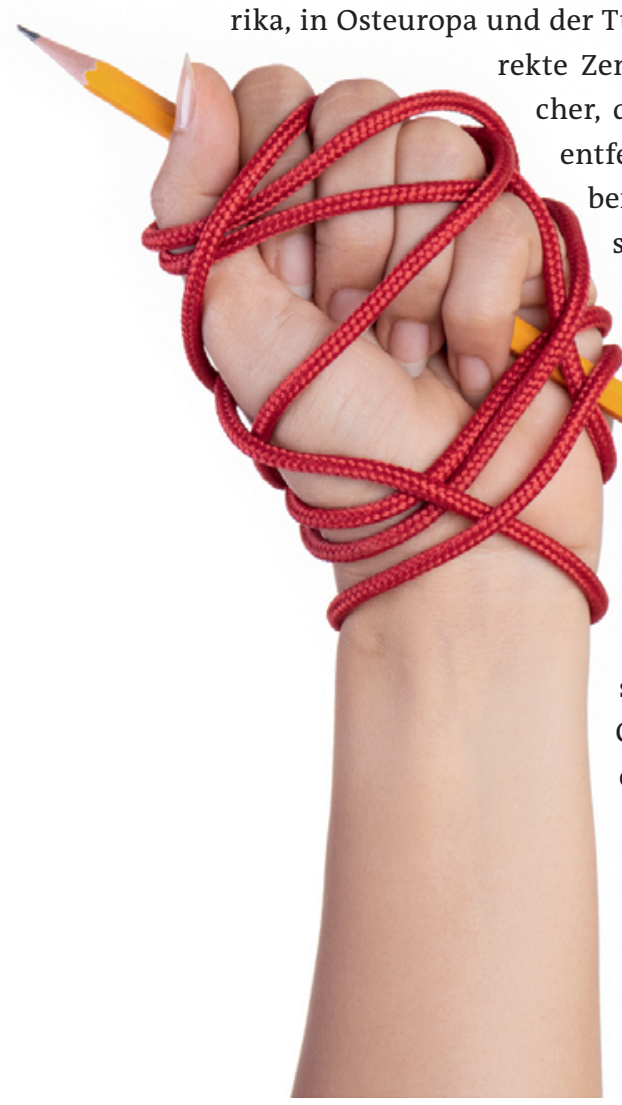

erhard.taverna[at]saez.ch weniger Pressefreiheit, ab 1848 ausdrücklich in der Verfassung des Bundesstaates garantiert. Ein Bundesratsbeschluss von 1934 sah vor, im Falle «schwerer Ausschreitungen» Warnungen oder Verbote auszusprechen.

Zensur wird in erster Linie im Internet ausgeübt. Websites werden gesperrt oder der Internetzugang abgeschaltet. Für eine Netzsperre entschieden sich 2018 die Abstimmenden im Falle des Geldspielgesetzes mit einem Verbot ausländischer Anbieter von Glücksspielen. Der einseitige Branchenschutz sollte die Einnahmen

Wer im Netz unterwegs ist, muss bedenken, dass Überwachung und Zensur nahe beieinander liegen.

für AHV, Sport und Kultur vor der Konkurrenz schützen. Ein bisher einmaliger Fall einer demokratisch festgelegten Zensurmassnahme. Ebenso reibungslos wurde im Namen der Terrorismusabwehr eine Vorratsspeicherung aller Internetdaten für sechs Monate eingeführt. Zu den Massnahmen gehören auch Staatstrojaner, die von der Justiz angeordnet werden können. Wie immer gibt es Wege, die Blockaden zu umgehen. Über verschlüsselte private Netze wie VPN, Psiphon oder Shield. Am bekanntesten ist wohl TOR, ein Router, der über eine Kette von verschiedenen Browsern die Anonymität der User sichert.

Über eine Abhörzentrale in Zimmerwald laufen alle Daten des Überwachungsprogramms Onyx, das der Bund als militärisches Geheimprogramm im Jahr 2000 installierte. Edward Snowden hat teuer für die Offenlegung des Schnüffelstaates bezahlt. Wer im Netz unterwegs ist, muss bedenken, dass Überwachung und Zensur nahe beieinander liegen.

Zum Schluss eine kleine Nachricht aus Seldwyla. Eine skurrile Geschichte nahm 1958 ihren Lauf, als der Bundesrat die Aufführung des Hollywood-Kriegsfilms Wege zum Ruhm untersagte. Ein Film, der die Folgen sinnloser Befehle französischer Offiziere aufzeigte. Eine Eingabe der damaligen Kulturelite landete beim Staatsschutz, der zahlreichen Kritikern Nähe zur Friedensbewegung und linksextreme Tendenzen unterstellte. Wegen angeblicher Belastungen unserer Beziehungen zu Frankreich blieb der Film zehn Jahre auf dem Index. Dies obwohl das Nachbarland nie intervenierte. 